\title{
Popular Music in Audio-Visual Advertising: A Study of the Roles and Functions of Lyrics in TV-Commercials
}

\author{
Tatiana Anisimova \\ Jönköping International Business School \\ P.O Box 1026. S-55111 Jönköping. Sweden \\ Tomas Müllern \\ Jönköping International Business School \\ P.0 Box 1026. S-55111 Jönköping. Sweden \\ Tonya Plachkova \\ Jönköping International Business School \\ P.0 Box 1026. S-55111 Jönköping. Sweden
}

\begin{abstract}
The use of popular songs is one of the most common methods in connecting with the audience in mass advertising. Advertisers are in search for the right melody or a song that can best connect a product and a brand to consumers' aspirations. The extant literature advocates the importance of a match or congruency between the song in the advertisement and a brand to avoid misinterpretation of the advertising message. Based on the analysis of 96 Levi's TV commercials, the current study looked at how lyrics in popular music of TV commercials are used and how they fit with the overall brand message and related elements of the commercial.
\end{abstract}

Keywords: Popular music, advertising, lyrics, congruency, brand associations.

\section{INTRODUCTION}

The use of music in advertising has a long history, and it is viewed as a strong platform for creating moods in advertising (1-2), to tap in on specific subcultures and target groups (3), and to get consumer attention (4). Considering the importance of music in many forms of advertising, and particularly in TV-commercials, it is somewhat surprising that the scholarly interest in music and advertising did not gain momentum until the late 1980s. The predominant research stream has focused on consumer-oriented studies of the affective and behavioral effects of music in advertising. Within this stream the effects of different structural elements of music (e.g. mode, tempo, pitch, rhythm and harmony) on dependent variables such as attitudes, purchase intentions, brand recognition and brand recall have been studied (5-7). The concepts of congruency and fit have attracted a lot of attention, studying fit between ad content and the audio-visual elements and how it is forming consumer perceptions of the commercial and their behavior (8-10).

The marketing literature implies that congruency helps in building a better brand communication with consumers (e.g. 11). Brand communications is viewed as a critical integrative element in managing brand relationships with consumers (12). Brand communication was found to play an important role in creating favorable brand attitudes (e.g. 13) and is a key to 'tangibalize' product and brand perceptions (14). Deciding on effective brand communications represents a major challenge for the marketers, as these are central to 
building consumer perception and consumer choices (e.g. 15-16). As consumers continue to bridge and co-develop brands with or without support of firms, their interaction, including their own communication, is becoming crucial to understanding brand communication practices (14).

The current study is motivated by the following observations. Firstly, despite the evidence of the important role music plays in commercials, little is known about what strategies are used to integrate music in commercials. Secondly, little attention has been devoted to how the elements of music, including lyrics, storyline, voice-overs, and text elements are all functioning as a totality in various purchasing and pre-purchasing settings. Thirdly, the previous literature appears to be preoccupied with the importance on building more explicit congruency between the brand or a product and structural elements of music (e.g. mode, tempo, pitch, rhythm and harmony) as a prerequisite of a positive impact on consumers' responses and behavior (e.g. 8, 17-18).

Drawing on research from film studies (19-20) it is argued here that music needs to be viewed as an integrated part of a whole, and that each component is understood as a part of this whole. The different elements of the commercial (brand/product, audio (music, dialogue, voice-over, and sound effects, text and other visual elements) need to be connected and understood as an interacting whole.

Based on the analysis of 96 Levi's Jeans TV commercials, this article analyzes how the lyrics in popular songs are integrated in commercials, and how they interact with other elements in the commercial, such as the storyline, main characters, brand associations and overall brand communications. Levi's Jeans has a history of using popular songs in their commercials. As argued by Moshini (21) the lyrics of a song plays a dramaturgical role in filmic texts, and TVcommercials are just a special case of this. Although filmmakers traditionally have placed music in the background, the "MTV-inspired" makers of TV-series, movies and TV-commercials tend to place the music more in the foreground, and this makes lyrics equally important as other elements such as screen dialogues. This observation opens up for interesting questions on how the lyrics are incorporated in a TV-commercial, to fit with other elements of it.

The purposes of the article are as follows:

- To analyze how lyrics interact with the story line of the commercial, main characters, brand associations, and the product itself.

- To determine if congruency exists between the song, the story line of the commercial, main characters, brand associations, and the product itself

- To assess the role of congruency in the overall brand communications

\section{THEORETICAL FRAMEWORK}

A TV-commercial is a complex art object that carries a combination of verbal (ad copy, voiceover and lyrics in music), visual (the story line and other visual components), and sonic (music and other sound effects) features. Vocal music in commercials is, by definition, both verbal and sonic, and it is connected to the visuals in a variety of ways. A central distinction is if the music is in the background or foreground of the commercial, with foreground music playing a more central role in the commercial and more directly enforcing itself on the viewer. A second important distinction is if the music is diegetic or non-diegetic (22-23). Diegetic means music whose source is visible on the screen or whose source is implied to be present by the action of the film, and non-diegetic music is music that is put on top of the commercial and it is not heard by the actors appearing in the video as mood music, coming from a space outside the 
story event. In our sample the music is always in the foreground and most of the commercials (around 90\%) are non-diegetic.

The inclusion of music in commercials depends to some extent on what type of music is used, for instance if the music is originally written for the commercial or if it is licensed, popular music. In the case of original music the different elements of the music (tempo, mode, lyrics and so on) can be controlled and adapted to the purpose of the single commercial and to the broader campaign. The case with pre-existing, licensed music (what we here refer to as popular music) is different with considerable less control over the music and how it can be incorporated in the commercial. Considering the importance of popular music in advertising (24-25) the use of it in commercials deserves special attention. It is clearly so that using popular songs has a big value in creating attention, building brand loyalty, creating identification with the product and the brand. Less is however known about the intricacies involved in incorporating popular music in the commercial.

A dominant research tradition within the music in advertising area focuses on the fit (or congruency) between music and other elements of TV-commercials, and how it influences dependent variables such as attitude and mood, brand recall and purchase intention (e.g. 8. 26). Park \& Young (27) described the role of background music as a peripheral persuasion cue that has a moderating effect on the attitude towards an advertisement. They proposed that the background music indirectly influenced brand attitude through its effect on the consumers' evaluation of the advertisement or their affective feelings for it. A theoretical backbone for the musical fit tradition is the Elaboration Likelihood Model (ELM) which suggests that attitude change appears through either a central route or a peripheral route. Park \& Young (27) hypothesized in their article that music affects brand attitudes through the peripheral route, and thus influences attitude indirectly.

Musical fit refers to the link between the music and attributes of a certain product (28-29). Gorn et al (30) found that high congruity between musical genre and product attributes enhanced recall of visual images from the commercial. In a similar way a number of authors found that the use of original music (e.g. jingles) increased recall of the brand. Macinnis \& Park (31) defined musical fit as a consumer's subjective perceptions of the music's relevance to the ad message. Zander (32) stated that music has the potential to affect customers beyond putting them in a good mood. Music can, if associated with spoken words, give a notional sharpness which is more effective than speech itself.

Kellaris, Cox \& Cox (33) introduced the concept of music-message congruency. It refers to the congruence between nonverbal meanings carried through the music in the commercial and the verbal in the ad copy. A similar idea was put forward by Gorn (30), claiming that the feelings the consumer has for a piece of music transfer to a product when they are paired in an ad. Oakes (34) reviewed and analyzed empirical studies on cognitive and affective responses to music in advertising. He categorized his findings by distinguishing between 10 variants of music/advertising congruity. Score, image, tempo, and timbre congruity were reported to enhance visual recall and led to more positive brand attitudes.

Yeoh \& North (29) tested the influence of musical fit on product choice by offering consumers a choice of different products while playing corresponding background music for one of the choices. In line with previous research their results suggest that musical fit may have an impact on product choice if consumers do not have a clear preference for selecting one product over the other. 
The musical fit studies give important support to the notion of links between different elements of a commercial. The above summarized studies do not, however, study the specific role of lyrics. The literature on how lyrics are incorporated in commercials is scarce and it only partially describes the variety of ways in which lyrics are connected to the rest of the commercial. Murray \& Murray (35) is an early example of a study that pinpointed the functions of lyrics. Lyrics perform a number of functions in a commercial, for instance:

... Creating a sense of relaxation, developing empathy, gaining attention, carrying news, creating imagery, carrying attribute and benefit information, or subtly communicating cultural values (35).

Roehm (6) studied the use of instrumental versus vocal versions of popular music, and the relative effectiveness of each of the two methods in musically presented brand messages (as measured by brand recall). The primary function of lyrics, according to Roehm, was to state the core brand message. Chou \& Lien (25) studied the advertising effects of a songs' release period (nostalgia) and the lyrics' relevance to the product. They defined lyrics' relevance as the degree of match between the lyrics and the advertised product, which is a similar connection as both Murray \& Murray (35) and Roehm (6) are suggesting. All three of the aforementioned studies $(6,25,35)$ hinted at other functions of the lyrics without specifying which. Alpert \& Alpert (36) found two main functions for the lyrics in vocal music in advertising. Either the lyrics carried the ad's verbal message and meaning directly, or they did not carry them directly (in the sense of not speaking directly about the product). Unfortunately they did not specify what other functions the lyrics could play if not carrying the ad's message.

It is evident from this literature review that the primary function of lyrics in commercials is proposed to be to carry the meaning of the product, which is in line with the argument from the musical fit and congruency studies. It is here claimed, in contrast to this view, that the lyrics are in fact used in a variety of different ways in commercials. Allan (24) gave support to this view in his study on music placement in prime-time TV advertising. In his set of commercials containing popular music only $28 \%$ had some sort of relevance for the advertised product, whereas $91 \%$ were linked to the narrative of the commercial.

As opposed to visual identity, whether in the form of a logo or a color scheme that has been a primary focus of both brand owners and their agencies, the role of audio branding, is underresearched and undervalued (37). This article analyze how the lyrics in popular songs are integrated in commercials, and how they interact with the storyline, main characters, brand associations, and other elements in the commercial. Based on the analysis of 96 TVcommercials for one brand (Levi's) a taxonomy is developed of different ways to incorporate lyrics in TV-commercials and their significance for advertising is discussed. It is not argued that one of the ways is more effective than another (this would be a subject for future studies based on our taxonomy). The ambition is very straightforward - to describe the ways in which lyrics are incorporated in a commercial, which puts the focus on the actual design/construction of commercials.

\section{METHODOLOGY}

Following the work of Graakjaer \& Jantzen (38) this article advocates a more qualitative approach to studying music in advertising, acknowledging the fact that music does not appear in isolation from its inner and outer context. In our case the inner context is the totality of verbal, visual and sonic features of the commercial (36). The inner context is the focus of this article, where an inductive, textual approach is used to develop a taxonomy of how lyrics are 
integrated in the commercial in a series of TV-commercials for one brand. The choice of focusing on one brand was deliberate and based on the decision to try to minimize the number of contextual factors. By using only one brand it was avoided having the brand influencing the analysis, and make it easier to generate categories. Differences between the commercials in the sample could then more accurately be attributed to the techniques used for integrating music and lyrics in the commercial, rather than reflecting differences between brands. In line with interpretivist views on music in advertising (39) it is here also argued that a "one-brand approach" makes it easier to reach a deeper understanding of the inner context for the ads. In future research there is, however, a need for testing the categories on a much wider selection of brands.

The methodological approach is inspired by the critical musicology that study music in an audiovisual context (19). In TV-commercials the music appears simultaneously with text units, voice overs, a visual story line and other components, making it an inseparable whole. Additional inspiration for the inductive and textual approach used in this study comes from recent work on the semiotics and hermeneutics of film $(23,40)$. Hung (41) argues, in a similar vein, for acknowledging semantic properties in music to enrich studies on advertising. An early example of adopting a more textual approach is Scott's (42) study on jingles in advertising. Numerous film studies have shown how non-diegetic film music help advance the dramatic development in the movie. Although the format and context of a TV-commercial is different from a movie, the techniques for analyzing the links between the music and the movie are highly relevant for our purposes. In our case it consists of uncovering the story line of the commercial and noting where in the story line the music and especially the lyrics appear. An example of how this is done in analyzing a TV-commercial is Pekkilä (43).

The data material for this article initially consisted of 125 TV-commercials for Levi's that were collected from various public sources. The selection of commercials gives both a deep and varied picture of how Levi's TV-commercials are constructed. The empirical analysis proceeded in three steps. In the first step an inductive, and explorative analysis was made of a random selection of 20 commercials from the sample. A detailed account of the storyline of each commercial was written and the lyrics were written down verbatim when they appeared in the storyline. Based on the written account of each of the 20 commercials a first, tentative analysis was made on how the lyrics were linked to the commercial. The ambition was to generate categories to describe different ways of linking lyrics to what appears in the commercial. A first selection of 7 categories were generated in this explorative step. It was also decided to include an 8th category with no apparent or loose connection between lyrics and what is seen and heard in the commercial, which was a category that appeared in some of the commercials.

In the second step various measures were taken to substantiate the categories and to make sure they were properly defined. Based on earlier research some support for the categories were found (44), although the general conclusion is that there is a big lack of research on the ways lyrics are incorporated in TV-commercials. In this step a reduction of the number of categories was made from 7 down to 4.3 additional categories were created covering ads without lyrics, music or only a loose connection between the lyrics and the other elements. Furthermore, a total of 15 of the 125 commercials were excluded from the analysis for various reasons, primarily because artist and/or lyrics could not be identified, leaving us with 110 useful commercials. 
In the third step the whole sample of 110 commercials was analyzed and categorized using the 4 substantial categories, and the 3 additional categories (loose connection, no lyrics, and no music). In the total sample of 110 commercials, 96 contained music and 14 had no music which is consistent with previous studies suggesting that $80-90 \%$ of all TV-commercials contain music (ref). In the sample of 96 commercials with music, 58 commercials came with lyrics and 38 were instrumental, which is substantially more than the results in Allan (24), where only $14 \%$ was classified as popular music (all ads with lyrics in our sample are classified as using popular music, and a number of the instrumental pieces are also popular music). It is clearly a deliberate choice of Levi's to use popular music rather than "needledrop" music.

\section{RESULTS AND DISCUSSION}

In this section of the paper the empirical results are presented and discussed. The connections of the lyrics with the other elements of each commercial were examined only within the context of the particular commercial and to the extent they are used in the commercial. There is a main focus in each advertisement where the creative idea has been realized connecting the lyrics with one of the four substantial categories. It is, however, important to notice that most of the analyzed commercials also have one or more secondary foci that serve as supportive surroundings for creating the whole creative story. This specification is needed in order to distinguish one commercial from another and the particular category they belong to. In many cases the connection between the lyrics and the other parts of a commercial contained more than one focus and to avoid that they are classified in two or more categories a clear distinction between the main and secondary focus was made. The classification of each of the commercials was validated in each of the three steps of the steps described above, and the classification was also substantiated by always letting two or more members of the research team give a second opinion on the classification.

In the following table all the categories are displayed together with the main and secondary focus to them and the number of commercials that fall into each category. Below the diagram a description of each of the 4 substantial categories is presented along with 2 examples that include a short description of the story line and the incorporation of the lyrics in a commercial.

Table 1: Summary of the empirical results of the study

\begin{tabular}{|c|c|c|c|}
\hline Category & Main focus & Secondary focus & $\begin{array}{c}\text { Commercials }=\text { in } \\
\text { total } 125\end{array}$ \\
\hline $\begin{array}{l}\text { Focus on the } \\
\text { emotions }\end{array}$ & $\begin{array}{l}\text { - emotions/feelings of the } \\
\text { character/s in tight relation } \\
\text { to what is seen on the } \\
\text { screen } \\
\text { - evoke emotions/feelings in } \\
\text { the spectator in tight } \\
\text { relation to what is seen on } \\
\text { the screen }\end{array}$ & $\begin{array}{l}\text { - narrative } \\
\text { - main character's image } \\
\text { relation to the character } \\
\text { with the product/brand }\end{array}$ & 7 \\
\hline $\begin{array}{l}\text { Focus on the main } \\
\text { character's image }\end{array}$ & $\begin{array}{l}\text { main character's image- its } \\
\text { features, qualities, behavior, } \\
\text { physical appearance, etc. }\end{array}$ & $\begin{array}{l}\text { - } \text { narrative } \\
\text { emotional condition of } \\
\text { the character/s } \\
\text { relation of the } \\
\text { character/s with the } \\
\text { product/brand }\end{array}$ & 7 \\
\hline
\end{tabular}




\begin{tabular}{|c|c|c|c|}
\hline $\begin{array}{c}\text { Focus on the } \\
\text { narrative }\end{array}$ & - Narrative & $\begin{array}{l}\text { - emotional condition of } \\
\text { - main character/s } \\
\text { - relation of the } \\
\text { character/s with the } \\
\text { product/brand }\end{array}$ & 16 \\
\hline $\begin{array}{l}\text { Focus on the } \\
\text { relation of the } \\
\text { character's with } \\
\text { the brand/product }\end{array}$ & $\begin{array}{l}\text { - } \text { encourage and appeal for } \\
\text { product/brand purchase by } \\
\text { suggesting that if the } \\
\text { spectator has the } \\
\text { brand/product they will be } \\
\text { happy, successful, not } \\
\text { lonely, beautiful, stylish, etc. } \\
\text { - the reckless need of the } \\
\text { character/s to have the } \\
\text { brand/product } \\
\text { - the devotion of the } \\
\text { character/s to the } \\
\text { brand/product }\end{array}$ & $\begin{array}{l}\text { - narrative } \\
\text { - main character's image } \\
\text { emotions/feelings that } \\
\text { attachment of the } \\
\text { character/s to the } \\
\text { brand/product }\end{array}$ & 14 \\
\hline Loose connection & & & 14 \\
\hline No lyrics & & & 38 \\
\hline No music & & & 14 \\
\hline $\begin{array}{l}\text { Not categorized- In } \\
\text { the commercials } \\
\text { from this category } \\
\text { the lyrics or/and } \\
\text { artist could not be } \\
\text { identified. }\end{array}$ & & & 15 \\
\hline
\end{tabular}

\section{Focus on the emotions}

Description: When emotions play a central role in a commercial, lyrics are used to either name the character's emotions or trigger emotions in a spectator that are related to the story shown on the screen. The connection between the lyrics and the story is direct and enhance the emotional aspect of the commercial.

Examples: In a commercial that exemplifies this category lyrics are used as a continuation of the visual part of the story telling. A young couple is getting separated because the man is going to military service and while they are taking their farewell at a bus station the lyrics accompany the story "When a man loves a woman he can't keep his mind on nothing else, he'll trade the world for the good thing he's found...". When she gets home and lies down on a bed crying with the package he gave her before he left the lyrics continue telling his love story "If she is bad he can't see it, she can do no wrong... Turning back on his best friend if he put her down... When a man loves a woman...". The creative approach in this commercial is focusing on the cheerless fact of dividing a couple in love by using lyrics that speak about the strong feelings of the character in order to add dramatic effect to the story.

In other examples of this category the lyrics reveal hidden meanings or emotions. They don't speak directly of what is seen on the screen but rather continue the story further. This is the case with a commercial when a young boy and a girl are helping each other to undress, looking into their eyes and telling how scared they are and that the first time nobody is good. Right before they jump from a pier they are holding each others' hands and the lyrics start 'Don't 
they love you in mysterious ways, You say yeah but this is now and that was then...”. These lines speak about nostalgia and trigger nostalgic emotions in a spectator - emotions that are not shown on the screen but the lyrics bring them as a complementation to the visual part of the commercial.

\section{Focus on the main character's image}

Description: When the main focus of a commercial is the main character's image the video mainly shows distinctive features of this image with the aim to trigger associations and the accompanying emotions with them. In this case lyrics are used to build and reinforce the creative idea of focusing the audience's attention to the main character's image.

Examples: In most of the cases within this category the main character is stereotypical and lyrics are used to underline this image which from its side carries strong semantic messages. This usage of lyrics serves as a tool in creating a story to put the focus on the main character's image that evokes subconscious meanings in the audience. An example of such a commercial is a story that shows a "bad guy" released from a prison and a beautiful young woman that comes to pick him up. His image is emphasized even by showing a cockroach at the beginning of the commercial and lyrics summarize everything "I move like a cat, talk like a rat... Sting like a bee... oh babe, I wanna be your man... I'm your toy, your 20th century boy."

Another example is a commercial when the main character enjoys the attention of all women around and the envy of all man. When he appears in the commercial the camera focuses on his body and face - this way of introducing him puts him in a spot light. The lyrics then are used to accompany and underline his image "Now when I was a young boy at the age of five... My mother said I am gonna be gonna be the greatest man alive. But now I am a man way past 21 . When I make love to a woman she can't resist. I want you to believe me baby. I had lots of fun. I'm a rollin' stone..."

\section{Focus on the narrative}

Description: In this case lyrics are used to describe the story itself or to serve as a storyteller by supporting the visual part of a commercial. Examples of this connection are lyrics that are used as a dialogue between the characters, complement the story line by giving additional information or repeat what is shown on the screen. All in all, lyrics in such connections with a commercial underline the narrative.

Examples: Lyrics serve as an emphasis of the story when they verbalize what is seen on the screen. The perception of the visual part of the story then is stressed and it becomes a central part of the commercial. This is the case with a commercial when a young girl and a man undress each other while their hair styles changes and new layers of clothes appear below. The visuals are very dynamic, everything happens in a fast and passionate way. The tension increases with each new layer of clothes. The lyrics clearly underline the visuals: "Oh, once I had a strange love, a childlike but deranged love, a love that if were bottled it would kill, yes once I had a strange love, a pure but very pained love, a love that burned like fire trough a field, you see I've had some strange love, some good, some bad, some plain love, some so-so love, and c'est la vie...".

Another commercial that exemplifies very well the usage of lyrics in this category is an ad where a young man a woman walk through different surroundings and meet each other at the end of the commercial where it becomes clear that they have walked towards each other the whole time. The lyrics serve as a dialogue between them when a male voice sings: "I keep a 
close watch on this heart of mine... I keep the ends out for the tie that binds..." and a female voice answers also with singing "I keep my eyes wide open all the time... Because you're mine, I walk the line..." And the two voices continue together: "I find it very, very easy to be true I find myself alone when each day is through Yes, I'll admit I'm a fool for you because you're mine, I walk the line."

\section{Focus on the relation of the character/s with the brand/product}

Description: When the creative idea is to focus on the importance of having a brand/product, lyrics are used as a verbal explanation of the relation between the character/s and the brand/product. They serve as an unambiguous message for the audience of how important/cool/necessary it is to have this brand/product.

Examples: In this category lyrics are used to underline the importance of the brand/product to the main character with the aim that a spectator will recognize himself/herself in it. An example for this is a commercial where the main character enters a night club for the only reason that he wears black Levi's in contrary to most of the people that are not permitted to enter because they are with blue jeans. All women turn after him while he walks inside with self-confidence. Lyrics say: "When the night has come, and the land is dark... And the moon is the only light we'll see... No I won't be afraid... Just as long as you stand, stand by me... And darlin', darlin', stand by me...". In this case the product is the "darling" that encourages the main character to not be afraid just as long as it stays by him.

Another example of this category is a commercial where the main character throws stones at a building's windows and when a young beautiful girl shows he hides himself behind a car. This repeats twice. The visuals suggest that he is trying to reach a girl that he is attracted to or in love with. The real purpose of his actions is revealed when a woman twice his age appears on a window and it looks like they know each other. She opens a room downstairs where he gets his pair of Levi's jeans obviously relieved from the fact that he wears them again on himself. While the story tricks a spectator's mind the lyrics speak about the main character "relation" with the jeans "I never thought I'd miss you half as much as I do... And I never thought I'd feel this way... The way I feel about you... As soon as I wake up Every night, every day I know that it's you I need To take the blues away It must be love, love, love, It must be love, love, love, Nothing more, nothing less Love is the best ..."

\section{Loose connection}

Description: Not clear or too vague connection of the lyrics with the other elements of the commercial or no connection at all.

\section{DISCUSSION AND CONCLUSIONS}

The main purpose of this article was to analyze how the lyrics in popular music is integrated in commercials, and how they interact with other elements in the commercial, such as the storyline, main characters, brand associations and overall brand communications. The main results of the study should be viewed in relation to the theoretical starting point of this study, the established congruency/fit theory, which suggests a tight fit between the lyrics and the product/brand related message. The four major functions of the lyrics in our sample suggests a broader palette of functions than just enhancing the product message. Our research shows that the lyrics can be instrumental in enhancing a much more varied group of reactions, including both emotions and identification. We know from studies of consumer culture, brand identity and image, but also organizational culture and identity, that processes of emotional bonds and 
identity are important markers of belonging and adherence, and we see clearly that the lyrics in our sample tap in on these processes.

The article does not try answer the question of how effective the use of instrumental and/or vocal popular music is in the context of TV-commercials. Based on our analysis, a few observations can, however, be made. As was mentioned above, Levi's pays a lot of attention to the use of popular music, with the lyrics fulfilling important roles in the commercials. Music is clearly more important for Levi's compared to other tools and techniques of the TV commercial. For instance, they rarely use celebrities in Levi's commercials, although there are a handful of exceptions (for instance with Brad Pitt appearing in a commercial). This is somewhat counterintuitive considering the proven effectiveness of using celebrities in commercials (45). The celebrity endorsement literature is connecting to similar cognitive factors as the musical fit literature as reported above. In particular celebrity and brand congruency is a familiar theme in the celebrity endorsement literature (45-46). On the other hand, Levi's not strongly using celebrities in their advertising can be due to potential detrimental effects that the use of celebrities in advertising can cause. These include a 'celebrity vamping', when the endorsing celebrity is too attractive and can draw attention away from the product (47) or possible consumer skepticism about whether or not endorsers really consume the product they endorse (48).

A strong reliance on vocal music has continued in Levi's commercials up to this day, which is an interesting result in comparison to other studies pointing at a decrease in the use of vocal music over time $(22,24)$. Contrary to earlier results it seems like Levi's have consistently moved in the opposite direction relying to a large extent (more than $80 \%$ in our sample) on vocal music, carrying a number of different roles and functions in the commercials.

The four categories of connections between lyrics and the rest of the commercial suggest three principal ways in which the company (or rather the brand) can reach out to their preferred audiences, using three rhetorical strategies. The first way refers to the rhetors duty of evoking feelings among the members of the audience, which is used in 7 of the commercials (focus on emotions). The emotional component in music has been acknowledged by a number of scholars studying music in advertising (44). Although the emotional appeal is not directly speaking about the product or the brand, the literature still suggests a spill-over effect to the product/brand by creating a positive mood $(31,49-50)$. This is also in line with results from the musical fit tradition were music is said to operate indirectly through the peripheral route $(9,36)$.

A second principal way of reaching out to the audience is through processes of identification (focus on the main characters image and focus on the relation of the character/s with the brand/product). In our material this is done in two different ways, either through identifying with the main character or through a more direct identification with the brand/product.

The third rhetorical strategy uses storytelling (focus on the narrative) to connect lyrics to the commercial. This is common strategy used in 16 of the commercials. Advertising in general, and TV-commercials in particular rely, to a growing extent, on storytelling. The importance of this rhetorical strategy is underlined by the growing literature on storytelling in marketing, the so called consumer storytelling theory (51), which in turn reflects the much broader "narrative turn" in the social sciences (52-54). 


\section{IMPLICATIONS}

Our analysis has several implications. From the analysis, it can be inferred that fit/congruency stretches beyond an explicit link between music and product/brand as the fit in music literature claims $(6,25,35)$. We accept that congruency or match between songs and the product sold in the commercial plays an important role in effectiveness of advertising. Music congruency was found to enhance affective responses to advertisements (see 34 for an example). Music consistency across all touch points has also been considered of the keys to building trust and loyalty (37). However, we argue that music and lyrics in the commercial should go beyond merely informing consumers about products but also communicate clear advantages that help to differentiate the brand from the competition and enhance brand equity. As with the development of the cinema, music sounds can offer the next level of communications for a brand (37). Brand communication was previously found to have favorable effects on the development of a trust-based platform between consumers and brands. For example, findings from the Grace and O'Cass (55) and Vazifehdust \& Norouzi, (56) studies suggest that brand communications play a pivotal role in establishing consumer expectations, thus influencing satisfaction and brand attitudes. One of the key aims of "audio branding" therefore should be to "plant" a set of brand triggers in consumer minds in the form of music (37).

Therefore, music and lyrics can be utilized as brand triggers that can help in enhancing brand communication and brand knowledge. Furthermore, brand names can reinforce consumer confidence and enhance brand trust. We recommend that future researchers look at these links in their research. Clearly, the intricacies of the process by which consumers evaluate differentiated products create a challenge for brands. Marketers are recommended not to overrely on the explicit link between the product and the brand and the song and take a more holistic view on the role of music and lyrics as an element enhancing effectiveness of brand communication.

\section{Bibliography}

1. Alpert, J. L. \& Alpert, M. I. (1990) ‘Music influences on mood and purchase

Intentions', Psychology and Marketing, 7(2), pp. 109-133.

2. Huron, D. (1989). 'Music in advertising: An analytic paradigm', Musical Quarterly, 73(4), pp. 557-574.

3. Bradshaw, A. Sherlock, R., and McDonagh, P. (2004) 'You say you want a revolution: Music in Advertising and Pseudo counterculture'. Conference papers, Paper 45.

4. Allan, D. (2006). 'Effects of Popular Music in Advertising on Attention and Memory', Journal of Advertising Research, 46(4); pp. 434-444.

5. Alpert, M. I., Alpert, J. I. \& Maltz, E. N. (2005) 'Purchase occasion influence on the role of music in advertising', Journal of Business Research, 58(3), pp. 369-376.

6. Roehm, M. L. (2001). 'Instrumental vs. vocal versions of popular music in advertising'. Journal of Advertising Research, 41(3), pp. 49-58.

7. Teng, L., Ye, N., Yu, Y., Wu, X. (2013). 'Effects of culturally verbal and visual congruency/incongruency across cultures in a competitive advertising context'. Journal of Business Research, 67(3), pp. 288-294.

8. Demoulin N. (2011) 'Music congruency in a service setting: The mediating role of emotional and cognitive responses', Journal of Retailing and Consumer Services 18(1), pp. 10-18. 
9. Lalwani, A.K., Lwin, M.O. and Ling, P.B. (2009) 'Does Audiovisual Congruency in Advertisement Increase Persuasion? The Role of Cultural Music and Products', Journal of Global Marketing, 22(2), pp. 139-153.

10. Wagner, M.S. (2008). 'Dimensions of Music: The Effect of Music/Brand Congruity on Advertising and Brand Evaluations.' Doctoral thesis, The University of Michigan.

11. Bryrum, K. (2010, August 11). Advertising Brand Messages. Corporate Brand.

12. Zehir, C., Sahin, A., Kitapci, H., \& Ozsanih, M. (2011) 'The effects of brand communication and service quality in building through brand trust: the empirical research on global brands'. Procedia: Social and Behavioral Sciences, 24, pp. 1218-1231.

13. Turley, L.W., \& Moore, P.A. (1995). 'Brand name strategies in the service sector'. Journal of Consumer Marketing, 12(4), pp. 42-50.

14. Centeno, E., \& Hart, S., (2012) 'The use of communication activities in the development of small to medium-sized enterprise brands'. Marketing Intelligence \& Planning, 30(2), pp. 250-265.

15. Aaker. D., \& Shansby, G. (1982) 'Positioning your product'. Business Horizons, 25(3), pp. 56-62.

16. Pham, M., \& Muthukrishnan, A. (2002) 'Search and alignment in judgment revisions: implications for brand positioning'. Journal of Marketing Research, 39(1), pp. 18-30.

17. Areni, C.S., \& Kim, D. (1993) 'The influence of background music on shopping behavior: classical versus top-forty music in a wine store', Advances in Consumer Research 20(1), pp. 336-340.

18. North, A.C., and Hargreaves, D., (1998) 'The effects of music on atmosphere and purchase intention in a cafeteria', Journal of Applied Social Psychology 28(24), pp. 2254-2273.

19. Bolivar, V.J., Cohen, A.J. \& Fentress, J.C. (1994) 'Semantic and Formal Congruency in Music and Motion Pictures: Effects on the Interpretation of Visual Action', Psychomusicology, 13(1-2), pp. 28-59.

20. Hoeckner, B., Wyatt, E.W., Decety, J. and Nusbaum, H. (2011) 'Film Music Influences How Viewers Relate to Movie Characters', Psychology of Aesthetics, Creativity, and the Arts, 5(2), pp. 146-153.

21. Moschini, I. (2011). 'Music and Series: The Verbalizing Role of Soundtrack Lyrics from TV series to Usergenerated Narrations', Visual Communication, 10(2), pp. 193-208.

22. Graakjaer, N.J. (2006) 'Musical Meaning in TV-Commercials', Popular Musicology Online.

23. Holbrook, M.B. (2004) 'Ambi-diegetic Music in Films as a Product-Design and -placement Strategy: the Sweet Smell of Success', Marketing Theory, 4(3), pp. 171-185.

24. Allan, D. (2008) 'A Content Analysis of Music Placement in Prime-Time Television Advertising'. Journal of Advertising Research, 46(3), pp. 404-417.

25. Chou, H-Y. \& Lien, N-H. (2010). 'Advertising Effects of Songs' Nostalgia and Lyrics' Relevance'. Asia Pacific Journal of Marketing and Logistics, 22(3), pp. 314-329.

26. Lam, S.Y., (2001) 'The effect of store environment on shopping behaviors: a critical review', Advances in Consumer Researc, h 28(1), pp. 190-197.

27. Park, C.W. and Young, S.M. (1986) 'Consumer Response to Television Commercials: The Impact of Involvement and Background Music on Brand Attitude Formation', Journal of Marketing Research, 23(1), pp. 11-24.

28. North, A.C., MacKenzie, L.C., Law, R.M. and Hargreaves, D.J. (2004) 'The Effects of Musical and Voice "Fit" on Responses to Advertisements', Journal of Applied Social Psychology, 34(8), pp 1675-1708. 
29. Yeoh, J.P.S. \& North, A.C. (2010) 'The Effects of Musical Fit on Choice between Two Competing Food', Musicae Scientiae, 15(1), pp. 165-180.

30. Gorn, G.J. (1982) 'The Effects of Music in Advertising on Choice Behavior: A Classical Conditioning Approach', Journal of Marketing, 46(1), pp 94-101.

31. Macinnis, D.J. and Park, C.W. (1991). 'The Differential Role of Characteristics of Music on High- and LowInvolvement Consumers' Processing of Ads', Journal of Consumer Research, 18(sep), pp, 161-173.

32. Zander, M.F. (2006). 'Musical Influences in Advertising: How Music Modifies First Impressions of Product Endorsers and Brands'. Psychology of Music. 34, pp. 465-480.

33. Kellaris, J.J., Cox, A.D. and Cox, D. (1993) 'The Effect of Background Music on Ad Processing: A Contingency Approach', Journal of Marketing, 57(4), pp. 114-125.

34. Oakes, S. (2007). 'Evaluating Empirical Research into Music in Advertising: A Congruity Perspective', Journal of Advertising Research, 47(1), pp 38-50.

35. Murray, N.M. and Murray, S.B. (1996). 'Music and lyrics in commercials: a cross-cultural comparison between commercials run in the Dominican Republic and in the US', Journal of Advertising. 25(2), pp. 51-63.

36. Alpert, J. L. \& Alpert, M. I. (1991) 'Contributions from a Musical Perspective on Advertising and Consumer Behaviour', Advances in Consumer Research, 18(1), pp. 232-238.

37. Fulberg, P. (2006) 'Using sonic branding in the retail environment - an easy and effective way to create consumer brand loyalty while enhancing the in-store experience', Journal of Consumer Behavior, 3(2), pp. 193-198.

38. Graakjaer, N.J. and Jantzen, C. (2009) (Eds.). Music in Advertising. Aalborg: Aalborg University Press.

39. Bode, M. (2009) 'Making Sense of Music in Advertising Research'. In Graakjaer, N.J. and Jantzen, C. (Eds.). Music in Advertising. Aalborg: Aalborg University Press.

40. McQuarrie, E.F. and Mick, D.G. (1992). 'Figures of Rhetoric in Advertising Language', Journal of Consumer Research. 22(4) , pp. 424-438.

41. Hung, K. (2000) 'Narrative music in congruent and incongruent TV advertising' Journal of Advertising. 25(1), pp. 25-34.

42. Scott, L.M. (1990). 'Understanding Jingles and Needledrop: a Rhetorical Approach to Music in Advertising'. Journal of Consumer Research, 17(2), pp. 223-236.

43. Pekkilä, E. (1997). 'Connotative Meaning and Advertising Music', Applied Semiotics, 2(4), pp. 119-131.

44. Bruner, G. C. (1990). 'Music, mood, and marketing', Journal of Marketing, 54(4), pp. 94-104.

45. Misra, S. and Beatty, S.E. (1990). 'Celebrity Spokesperson and Brand Congruence: An Assessment of Recall and Affect, Journal of Business Research, 21(2), pp. 159-173.

46. Kahle, L.R. \& Homer, P.H. (1985) 'Physical Attractiveness of the Celebrity Endorser: A Social Adaptation Perspective', Journal of Consumer Research, 11(4), pp. 954-961.

47. Rossiter, J.R. and Percy L. (1997). Advertising communications and promotion management. (2nd ed). International edition.

48. Hsu, C. and McDonald, D. (2002) 'An examination on multiple celebrity endorsers in advertising', Journal of Product \& Brand management, 11(1), pp. 19-29.

49. Alpert, J. I. \& Alpert, M. I. (1989) 'Background music as an influence in consumer mood and advertising responses', Advances in Consumer Research, 16(1), pp. 485-491. 
50. Kellaris, J.J. and Kent, R.J. (1992) 'The influence of music on consumers' temporal perceptions: Does time fly when you're having fun', Journal of Consumer Psychology. 1(4), pp. 365-376.

51. Woodside, A.G., Sood, S. \& Miller, K.E. (2008) 'When Consumers and Brands Talk: Storytelling Theory and Research in Psychology and Marketing'. Psychology \& Marketing, 25(2), pp. 97-145.

52. Czarniawska, B. (1997) Narrating the Organization. Dramas of Institutional Identity. Chicago: Chicago University Press.

53. Czarniawska, B. (2004) Narratives in Social Science Research. Los Angeles: Sage.

54. Clandinin, D.J. and Connelly, F.M. (2000) Narrative Inquiry. Experience and Story in Qualitative Research. San Francisco: Jossey-Bass.

55. Grace, D., and O'Cass, A. (2005) 'Examining the effects of service brand communications on brand evaluation', Journal of Product and Brand Management, 14(2/3), pp. 106-116.

56. Vazifehdust, H. \& Norouzi, A. (2011). 'The Effect of Service Brand Communications on Consumer Response'. European Journal of Social Sciences, 25(1), pp. 42-52. 